\title{
JUROS SOBRE CAPITAL PRÓPRIO NO SETOR ELÉTRICO BRASILEIRO
}

\section{INTEREST ON EQUITY IN THE BRAZILIAN ELECTRICAL SECTOR}

0 artigo foi aprovado e apresentado no X Congresso de Administração, Sociedade e Inovação (CASI), realizado de 30/11 a 01/12 de 2017, em Petrópolis (RJ).

\section{RESUMO}

As decisões relativas à política de remuneração do capital próprio, como a proporção dos lucros que é distribuída, a forma de distribuição, e seus impactos no valor das empresas, é tema recorrente na literatura de finanças corporativas, com o surgimento de diferentes teorias. $\mathrm{O}$ objetivo deste estudo é analisar os impactos decorrentes da escolha entre dividendos e JCP nas empresas de maior representatividade do setor elétrico, no período de 2011 a 2016, tendo como pano de fundo a otimização tributária, sob a ótica da empresa. Apesar de apresentarem similaridades conceituais perante a legislação, ambas as formas de distribuição de resultados possuem diferenças quanto ao regime de tributação em que estão inseridas. Durante o período amostral, verificou-se que quaisquer uma das vezes que se utilizou a distribuição de lucros pela composição entre dividendos e JCP, foi possibilitado um ganho fiscal para a empresa, gerando um impacto na carga tributária. Mesmo com as limitações legais e/ou operacionais impostas para o uso do JCP, tal ganho, segundo a simulação, em média foi superior a R\$ 68 milhões, apontando o benefício de se considerar uma combinação de distribuição de resultados.

Palavras-chave: Remuneração do Capital Próprio. Juros Sobre Capital Próprio. Dividendos.

\begin{abstract}
Decisions regarding the equity compensation policy, such as the proportion of profits that are distributed, the form of distribution, and their impacts on corporate value, is a recurring theme in the corporate finance literature, with the emergence of different theories. The objective of this study is to analyze the impacts arising from the choice between dividends and interest on capital in the most representative companies in the electricity sector, from 2011 to 2016, against the background of tax optimization, from the company's perspective. Despite presenting conceptual similarities before the legislation, both forms of distribution of results have differences as to the tax regime in which they are inserted. During the sample period, it was found that any of the times that the distribution of profits by the composition between dividends and JCP was used, a tax gain was made for the company, generating an impact on the tax burden. Even with legal and / or operational limitations imposed for the use of JCP, such gain, according to the simulation, averaged over $R \$ 68$ million, pointing to the benefit of considering a combination of distribution of results.
\end{abstract}

Keywords: Equity Compensation. Interest on Equity. Dividends

\section{João Eduardo Ribeiro}

Doutorando em Administração na Universidade Federal de Minas Gerais (UFMG). Mestre em Administração pelo Centro Federal de Educação Tecnológica de Minas Gerais (CEFET-MG). Graduado em Ciências Contábeis pela Universidade Federal de Viçosa (UFV). Membro do Grupo de Pesquisa Finance Research Group (GFIN). Contato: Avenida Presidente Antônio Carlos, 6627 - Sala 4012 Pampulha, Belo Horizonte - MG, CEP: 31.270-901. E-mail: joaoribeiro.cco@gmail.com.

\section{Gabriel Augusto de Carvalho}

Mestre em Administração pelo Centro Federal de Educação Tecnológica de Minas Gerais (CEFET-MG). Graduado em Ciências Econômicas pela Universidade Federal de Minas Gerais (UFMG). Membro do Grupo de Pesquisa Finance Research Group (GFIN). Contato: Av. Amazonas, 5.253, Nova Suiça, Belo Horizonte - MG, CEP:30.421-169. E-mail: ga09carvalho@gmail.com.

\section{Cláudia Faria Maciel}

Mestra em Administração pelo Centro Federal de Educação Tecnológica de Minas Gerais (CEFET-MG). Graduada em Ciências Econômicas pela Universidade Federal de Juiz de Fora (UFJF). Membro do Grupo de Pesquisa Finance Research Group (GFIN). Contato: Av. Amazonas, 5.253, Nova Suiça, Belo Horizonte - MG, CEP: 30.421-169. E-mail: cfariam@gmail.com.

\section{Ivan Fernandes da Cruz}

Mestre em Administração pelo Centro Federal de Educação Tecnológica de Minas Gerais (CEFETMG). Especialista MBA em Gestão de Negócios e Compras pelo Instituto de Educação Tecnológica (IETEC). Graduado em Administração pela Pontifícia Universidade Católica de Minas Gerais (PUC-Minas). Analista de Operações de Financiamento na Cemig Geração e Transmissão S.A. Contato: Av. Amazonas, 5.253, Nova Suiça, Belo Horizonte - MG, CEP: 30.421 169. E-mail: ivanfernandes26@bol.com.br.

\section{Antônio Artur de Souza}

Pós-doutor em Finanças pela Universidade de Grenoble. Ph.D. em Management Science pela Universidade de Lancaster. Mestre em Engenharia de Produção pela Universidade Federal de Santa Catarina (UFSC). Especialista em Educação a Distância pela Universidade Federal Fluminense (UFF). Graduado em Ciências Contábeis pela Universidade Federal de Santa Catarina (UFSC). Professor Associado IV da Universidade Federal de Minas Gerais (UFMG). Contato: Avenida Presidente Antônio Carlos, 6627 - Sala 4012, Pampulha, Belo Horizonte - MG, CEP 31.270-901. E-mail: artur@face.ufmg.br. 


\section{INTRODUÇÃO}

As decisões relativas à política de remuneração do capital próprio, como a proporção dos lucros que é distribuída, a forma de distribuição, e seus impactos no valor das empresas, é tema recorrente na literatura de finanças corporativas. Lintner (1956) aponta que os acionistas preferem ações com estabilidade ou crescimento de dividendos, e com isso as empresas tendem a obter uma maior valorização pelo mercado. Já Modigliani e Miller (1961) propõe o oposto dessa teoria, na visão dos autores o acionista é indiferente quanto à forma de distribuição dos dividendos, estando atentos apenas quanto à política de investimentos da empresa. Em outro estudo sobre o tema, Baker e Smith (2006) sugerem que as empresas somente devem pagar dividendos após terem explorado todas as oportunidades de investimento com um retorno esperado acima do custo de capital.

Esse debate ganha ainda mais relevância no contexto brasileiro, no qual os dividendos não são tributados e há ainda um mecanismo de distribuição de lucros que não existe em outros países: os juros sobre capital próprio (JCP) (Oliveira, 2018). Desse modo, a decisão do gestor ganha ainda mais relevância, pois é preciso ponderar o impacto que a forma de distribuição escolhida irá gerar nos custos para a empresa e para o acionista.

Os dividendos e o JCP possuem similaridades, uma vez que ambos se caracterizam como instrumentos de distribuição de resultados permitidos pela legislação brasileira, e somente poderão ser utilizados ser houver lucro líquido do exercício apurado, lucros acumulados ou reservas de lucros, conforme lei 6.404/76 e lei 9.249/95 e suas posteriores alterações. Apesar das semelhanças conceituais, as principais diferenças entre esses mecanismos concentram-se no regime tributário e restrições em relação ao montante total que pode ser distribuído.

Diante desse panorama, o objetivo deste estudo é analisar, sob a ótica da empresa, os impactos decorrentes da escolha entre dividendos e JCP nas companhias que compõe o Índice de Energia Elétrica (IEE) da Brasil Bolsa Balcão (B3). O período estudado compreende os anos entre 2011 a 2016 e tem como pano de fundo a otimização tributária da empresa. O Índice de Energia Elétrica (IEE) é um índice setorial da B3, que incorpora uma carteira teórica de ativos de maior representatividade do setor de energia elétrica, incluindo ações e units (Certificado de Depósito de Ações), de empresas negociadas na B3. O desempenho desse índice reflete o desempenho médio das empresas do setor em questão. A escolha do setor elétrico para compor a amostra desse estudo deve-se ao fato de possuir um histórico de bom pagador de dividendos em relação aos demais, conforme destacado por Decourt e Procianoy (2012). A opção pela utilização das empresas que compõe o IEE se justifica no fato de que na composição da carteira teórica são considerados critérios de negociabilidade e representatividade, sendo essas empresas consideradas as mais relevantes do setor.

Nesse sentido, uma análise empírica dos benefícios tributários oriundos da adoção do JCP como mecanismo de distribuição de lucros aos acionistas contribui com a literatura brasileira sobre o tema. Além disso, uma análise que mostra a relevância de se escolher corretamente a forma de distribuir dividendos pode contribuir para um planejamento tributário mais eficiente por parte das empresas que possuem essa opção.

\section{FUNDAMENTAÇÃO TEÓRICA}

O referencial teórico desse trabalho está dividido em três subseções, com vistas a apresentar os principais aspectos tangentes ao tema do estudo, bem como mostrar o estado da arte sobre a distribuição de resultados no Brasil. Na primeira subseção são apresentadas as principais teorias sobre o tema, posteriormente são tratados os aspectos legais da distribuição de resultados no mercado brasileiro, e por fim, são apresentados estudos empíricos recentes sobre o tema.

\subsection{A política de dividendos}

A política de dividendos de uma empresa está intrinsicamente ligada às decisões de como deverá ser distribuído os resultados ao acionista e como deverá ser reinvestido esse capital (Sousa Neto et al., 2014). Para Gomes, Takamatsu e Machado (2015) a determinação da política de dividendos pelas empresas é feita de forma a atrair determinado tipo de acionista, orientados para curto ou longo prazo. De acordo com Cioffi e Famá (2010) tal decisão deve ter como objetivo a maximização do valor da empresa para o acionista.

As relações entre o papel dos dividendos no retorno das ações e no custo de capital estão entre os temas mais relevantes no campo das finanças corporativas e diversas proposições sobre o assunto têm sido abordadas na literatura ao longo dos anos (Cioffi \& Famá, 2010). A teoria da Relevância dos Dividendos, que preconiza a existência de relação entre a política de dividendos de uma empresa e seu valor de mercado, é sustentada por diversos autores. Lintner (1956) considerado precursor dos modelos empíricos sobre a política de dividendos, sustenta que os gestores priorizam a definição da política de dividendos, e que as outras políticas da empresa seriam definidas posteriormente. Em seu estudo, o autor conclui que os acionistas preferem a estabilidade dos dividendos e que o mercado tende a valorizar as ações de empresas que apresentam estabilidade ou taxa crescente dos dividendos (Forti, Peixoto \& Alves, 2015).

Já Gordon e Shapiro (1956) postulam que, ao comprar uma ação de uma empresa, o acionista estaria interessado em toda a sequência de pagamento de dividendos futuros que poderia receber, e não apenas no valor atual, pois o preço pelo qual o investidor pode vender a ação posteriormente dependerá das previsões dos dividendos nesse momento. Gordon (1959) afirma que, para um investidor, mais vale um dividendo na mão do que um ganho de capital incerto. Essa suposição ficou conhecida como teoria do passado na mão que defende, portanto, que os investidores tendem a valorizar 
mais as ações das empresas que possuem um alto índice de distribuição de seus resultados (Loss \& Sarlo Neto, 2003).

Por outro lado, a teoria da Irrelevância dos Dividendos, de Modigliani e Miller (1961), postula que a forma como a empresa distribui seus dividendos é irrelevante para o valor de mercado da mesma. O que deve importar aos acionistas é apenas a política de investimentos adotada, ou seja, receber menos dividendos num determinado momento significa que a empresa pode financiar novos projetos que renderão aumento no pagamento dos dividendos num momento posterior. Outra teoria relevante sobre o tema é a teoria Residual dos Dividendos, que segundo Baker e Smith (2006) propõem que o pagamento dos dividendos deve ser efetuado após terem sido aproveitadas todas as oportunidades de investimentos com valor presente líquido positivo. Quando a necessidade de capital excede os lucros retidos, não se realiza a distribuição dos dividendos que, portanto, seria considerado um resíduo, uma vez exercidas as decisões de investimento (Sanvicente, 2017).

\subsection{Aspectos normativos da distribuição de resultados no Brasil}

No Brasil as empresas possuem três formas legais de distribuir seus resultados para os acionistas: a recompra de ações, a distribuição de dividendos e o JCP. Destaca-se que o JCP é uma peculiaridade do mercado brasileiro, que vem motivando diversos estudos com o objetivo de melhor compreender os impactos de tal forma de distribuição de resultados (Iquiapaza, Lamounier \& Amaral, 2006, Gouveia \& Afonso, 2012, Gomes, Takamatsu \& Machado, 2015).

O mecanismo de recompra de ações se caracteriza como uma forma de distribuição de resultados, pois com ele a empresa utiliza seus recursos para proporcionar um maior retorno para os acionistas remanescentes. Dessa forma, ao recomprar suas ações a empresa reduz a base de acionistas, fazendo com que o acionista remanescente seja beneficiado ao deter uma maior proporção do capital social da empresa, além de ocorrer a elevação do dividendo por ação. Gomes et al. (2015) apontam que, essa forma de distribuição dos resultados é bilateral, pois além da decisão da empresa de recomprar é preciso que os investidores desejem vender suas ações.

Já os dividendos, são definidos como a parcela do lucro reservada para remunerar o capital investido pelo acionista, sendo seus padrões de distribuição normalmente definidos pelo estatuto da empresa (Sá \& Sá, 1990). Sendo que, a Lei 6.404/76 deixa a cargo do estatuto a fixação da proporção do lucro líquido a ser distribuído, respeitando-se um mínimo de $25 \%$, já no caso de omissão do estatuto é definido que deverá ser distribuído no mínimo $50 \%$ do lucro líquido com os acréscimos e deduções estabelecidas. No caso de uma empresa de capital fechado a assembleia poderá deliberar, caso não haja oposição de qualquer acionista presente, a distribuição de dividendo menor do que 25\% do lucro.

Destaca-se que a legislação vigente no Brasil isenta os dividendos de impostos, tornando essa forma de distribuição dos resultados atraente sob a ótica do investidor. Assim, os dividendos constituem-se como um fluxo de caixa para os acionistas e também como um sinalizador do desempenho atual e futuro da empresa. A política de dividendos então está ligada a pagar ou não pagar dividendos e quanto devem ser pagos.

Com o advento do Plano Real, em 1995, por meio da Lei 9.249/95, foi extinta a correção monetária do patrimônio líquido. Essa mesma lei estabeleceu uma nova forma de remuneração para o acionista, o JCP. Os dividendos e o JCP possuem diferenças de natureza jurídica, obrigatoriedade legal, fundamento da remuneração e, sobretudo, a forma de tributação que cada um está sujeito (Gomes et al. 2015). Conforme estabelecido pelo caput do art. $9^{\circ}$ da Lei 9.249/95:

A pessoa jurídica poderá deduzir, para efeitos da apuração do lucro real, os juros pagos ou creditados individualizadamente a titular, sócios ou acionistas, a título de remuneração do capital próprio, calculados sobre as contas do patrimônio líquido e limitados à variação, pro rata dia, da Taxa de Juros de Longo Prazo - TJLP.

Para valer desse mecanismo, a empresa deve previamente estar atenta às condições impostas pela Lei 9.249/95, que determina que o pagamento do JCP somente possa existir quando houver lucro, ou lucros acumulados e reservas de lucros, sendo que o montante a ser pago não pode exceder $50 \%$ do lucro, ou reserva de lucros, quando for o caso. Ressalta-se que a lei permite que o valor pago de JCP pode ser imputado do valor do dividendo mínimo obrigatório estabelecido pela Lei 6.404/76.

Em relação à questão tributária que envolve o JCP, a lei determina que a empresa poderá deduzir os juros pagos aos acionistas, a título de remuneração do capital próprio, calculados sobre as contas do patrimônio líquido e limitados à variação, pró-rata/dia, da TJLP, que será contabilizado como despesa financeira e, desse modo, reduzirá o lucro tributável, gerando benefício fiscal para a empresa. Santos e Salotti (2009) destacam que o uso do JCP, a priori, culmina em uma economia para a empresa, diminuindo a carga tributária. Com relação ao acionista, destaca-se o fato de que, diferente do que acontece com os dividendos no Brasil, o JCP está sujeito à incidência de imposto de renda, com uma alíquota de $15 \%$ retida na fonte. Conforme aponta Brito (1999) o uso do JCP geralmente está ligado a uma estratégia utilizada para reduzir a carga tributária da empresa, contudo, conforme bem lembra o autor, é importante também considerar o impacto de tal forma de distribuição dos resultados para o acionista. Apesar disso, é importante o reconhecimento do JCP como mais uma alternativa para as empresas na busca pela eficiência tributária.

\subsection{Estudos empíricos sobre distribuição de resultados}

A figura do JCP e a não tributação dos dividendos faz com que o contexto da decisão da distribuição de resultados 
no Brasil seja distinto das nações que são referências para os principais estudos empíricos sobre o tema. Desse modo, são apresentados nessa seção, alguns estudos empíricos relevantes sobre a distribuição de resultados no contexto das empresas brasileiras.

Santos e Salotti (2009) procuraram elucidar qual o entendimento sobre JCP como forma de remuneração dos acionistas das empresas que operam no Brasil. Para tanto, o autor selecionou para a amostra 3.000 empresas que apresentaram em suas demonstrações contábeis em 2005, destinação de resultados a seus acionistas na forma de JCP. A metodologia do estudo consistiu na aplicação de questionários junto às companhias selecionadas, e os resultados apontaram que a maioria das empresas pesquisadas têm utilizado os limites legais de dedutibilidade, compensam os JCP com dividendos e obtêm vantagens fiscais nesse processo.

Malaquias, Giachero, Costa e Lemes (2007) investigam, para diferentes tipos de acionistas, se a dedução de JCP como despesa financeira está sempre relacionado com o benefício fiscal. Para tanto, os autores realizam três simulações envolvendo uma empresa pagadora tendo como acionista uma pessoa física, uma pessoa jurídica e uma empresa que se dividia entre ambos. Os resultados mostram que para acionistas pessoas físicas, a contabilização de JCP como distribuição de resultados pode ser tributariamente vantajosa, ao passo que para pessoas jurídicas tal situação já não se mostra favorável.

Decourt e Procianoy (2012) realizaram um survey com Chief Financial Officers (CFOs) de empresas listadas na B3, em dezembro de 2008, com a finalidade de conhecer o processo decisório da distribuição de lucros dessas empresas. Os autores identificaram que os principais fatores que são analisados para a definição dos dividendos são o lucro líquido do exercício e a geração de caixa do período. Foi constatado também que o uso do JCP é adotado pela maioria das empresas respondentes, devido ao benefício fiscal que essa forma de distribuição de resultados proporciona. Já a recompra de ações, apesar de se apresentar benéfica aos acionistas, é tratada pela maioria dos respondentes como uma decisão de investimentos. Buscando investigar a relação entre a distribuição de JCP e dividendos com o retorno das ações, Corso, Kasai e Lima (2012) utilizaram de uma amostra com 1.119 ações de empresas negociadas na B3, no período de 1995 a 2008. Os autores utilizaram de correspondência em painel. Os resultados do estudo indicam que a distribuição de JCP e dividendos apresentam relação inversa com o retorno das ações, confirmando a hipótese inicial do estudo.

Gomes et al. (2015) procuram observar os principais fatores que levam as empresas a decidir entre dividendos e JCP na distribuição de seus resultados. A amostra selecionada englobou 115 empresas de capital aberto listadas na B3, que distribuíram algum tipo de proventos no ano de 2012. O estudo utilizou de uma técnica de regressão logística para explicar os determinantes da política de distribuição de proventos e os resultados mostram que empresas do setor de construção e transporte tendem a distribuir dividendos, enquanto empresas com alto valor de mercado priorizam o pagamento de JCP. Dessa forma, os autores sugerem que, uma vez que o uso de JCP é mais vantajoso em relação a benefícios fiscais, o mercado tende a valorizar empresas que utilizam dessa forma de distribuição de resultados, aumentando seu valor de mercado.

Em um estudo recente, Fagundes e Petri (2017) analisam as vantagens do JCP como forma distribuição de resultados, a fim de alcançar o benefício fiscal sem que as empresas atuem na informalidade. Os autores afirmam que as empresas brasileiras acabam praticando a informalidade, com o propósito de diminuírem a carga tributária e assim, obter vantagens competitivas em seus custos. Para tanto, foram analisados os demonstrativos contábeis das empresas GOL e LATAM, no período de 2010 a 2015. Como não foi feito uso do JCP por nenhuma das empresas da amostra, os autores elaboraram uma simulação com o intuito de verificar qual seria a economia caso tivessem optado por essa forma de distribuição de resultados. As conclusões finais apontam que ambas obteriam um ganho financeiro de R $\$ 38$ milhões, confirmando a premissa inicial do estudo.

\section{METODOLOGIA}

\subsection{Delineamento da Pesquisa}

O objetivo desta pesquisa é analisar, sob a ótica da empresa, os impactos decorrentes da escolha entre dividendos e JCP nas companhias que compõe o IEE da B3. No tocante ao objetivo, esta pesquisa se caracteriza como descritiva, que segundo Gil (1999), representa um grupo de pesquisas que descrevem um fenômeno observado, sem nele interferir. No tocante à abordagem, os métodos utilizados neste estudo são quantitativos, pois possibilitam testar teorias, hipóteses, e/ou analisar os resultados encontrados (Creswell, 2015). Por fim, este estudo caracteriza-se como ex-post-facto no tocante aos procedimentos, que na visão de Gil (1999), é um tipo de pesquisa realizada a partir de fatos passados, em que o pesquisador não controla as variáveis, uma vez que elas já ocorreram, apenas identifica as situações que evoluíram naturalmente e trabalha com elas.

\subsection{Amostra e Tratamento dos Dados}

Para a amostra desse estudo, foram selecionadas todas as empresas que compõe a carteira teórica do IEE da B3, válida para os meses de janeiro a abril de 2018. O índice é composto por empresas de capital aberto mais significativas do setor de energia elétrica, justificando, portanto, sua escolha como objeto desse estudo. As 19 empresas da amostra são apresentadas na Figura 1, junto ao seu respectivo código de negociação (ticker). 
Figura 1 - Empresas que compõe a carteira teórica do IEE

\begin{tabular}{|c|c|c|c|}
\hline Ticker & Ação & Ticker & Ação \\
ALUP11 & ALUPAR & ENBR3 & ENERGIAS BR \\
CESP6 & CESP & ENEV3 & ENERGISA \\
CMIG4 & CEMIG & ENGI11 & EQUATORIAL \\
COCE5 & COELCE & EQTL3 & LIGHT S/A \\
CPFE3 & CPFL ENERGIA & LIGT3 & RENOVA \\
CPLE6 & COPEL & RNEW11 & TAESA \\
CPRE3 & CPFL RENOVAV & TAEE11 & AES TIETE E \\
EGIE3 & ENGIE BRASIL & TIET11 & TRAN PAULIST \\
ELET3 & ELETROBRAS & TRPL4 & \\
\hline
\end{tabular}

Fonte: Elaborada pelos autores.

Os dados para o desenvolvimento desse estudo foram obtidos das demonstrações financeiras consolidadas dessas empresas, disponíveis no próprio site da B3. O período amostral considerado para esse estudo é composto por seis anos com informações disponíveis, ou seja, o período de 2011 a 2016, ressalta-se que o período de 2017 apesar de estar disponível, não foi considerado, pois pode sofre reapresentações de resultados em função de erro e modificações de metodologias, nesse sentido prezando pelo princípio de prudência o ano de 2017 foi excluído da amostra.

De posse desses dados, a primeira etapa do estudo consiste em elaborar as estatísticas descritivas, a fim de apresentar informações como as médias de JCP pagos por essas empresas, assim como medidas de dispersão. Feito isso, através dos dados obtidos nas demonstrações financeiras e com o auxílio de simulações, propõe-se a inserção de pagamentos de JCP, considerando o limite dedutível, com vistas a destacar como essa alternativa poderia ser capaz de minimizar a carga tributária.

Essa análise sobre os impactos fiscais será sob a ótica da empresa. No entanto, deve-se ressaltar que a mudança na forma de distribuição dos resultados pela empresa acarreta mudança tributária para os investidores pessoa física, uma vez que são retidos $15 \%$ do Imposto de Renda (IR) na fonte. Dessa forma, alguns acionistas podem optar por receber dividendos com a devida isenção de impostos, do que pagar alguma alíquota, para assim obter um aproveitamento tributário.

Cabe destacar ainda o fato de que para explicitar o ganho ou perda tributária, foram considerados: a distribuição de resultados de no máximo 95\% dos lucros líquidos, excluindo a reserva legal (Lei 6.404/76), o teto dedutível para o JCP e os dividendos já distribuídos (Lei 9.249/95). O objetivo é demonstrar o impacto da forma de distribuição dos resultados na estrutura tributária da empresa ao final do período, após o pagamento de todas as obrigações da empresa, inclusive com sócios.

\section{ANÁLISE DOS RESULTADOS}

Inicialmente, são apresentados, por meio da Tabela 1, os dados reais das empresas que compõem a carteira teórica IEE e que em pelo menos um dos anos analisados distribuíram JCP aos seus acionistas. Ressalta-se que os valores aqui adotados, tal como disposto nas demonstrações contábeis das empresas, estão em milhares de reais.

Tabela 1 - Empresas que pagaram JCP aos acionistas (em milhares de reais)

\begin{tabular}{l|r|r|r|r|r|r} 
& \multicolumn{1}{|c|}{$\mathbf{2 0 1 1}$} & \multicolumn{1}{c|}{$\mathbf{2 0 1 2}$} & \multicolumn{1}{c|}{$\mathbf{2 0 1 3}$} & $\mathbf{2 0 1 4}$ & \multicolumn{1}{c}{$\mathbf{2 0 1 5}$} & $\mathbf{2 0 1 6}$ \\
\hline CEMIG & $1.207 .725,00$ & $1.700 .000,00$ & $533.149,00$ & $230.000,00$ & $200.000,00$ & 0,00 \\
COPEL & $421.091,00$ & $138.072,00$ & $180.000,00$ & $30.000,00$ & $198.000,00$ & $282.947,00$ \\
ENGIE BRASIL & $253.990,00$ & $276.200,00$ & $244.800,00$ & $223.000,00$ & $314.000,00$ & $432.500,00$ \\
ELETROBRAS & $360.933,00$ & $433.962,00$ & $433.962,00$ & 0,00 & 0,00 & 0,00 \\
ELETROPAULO & $73.039,00$ & 0,00 & 0,00 & 0,00 & 0,00 & 0,00 \\
ENERGIAS BR & $131.000,00$ & $130.422,00$ & $29.190,00$ & $133.300,00$ & $14.592,00$ & $336.851,00$
\end{tabular}




\begin{tabular}{|c|c|c|c|c|c|c|}
\hline & 2011 & 2012 & 2013 & 2014 & 2015 & 2016 \\
\hline LIGHT S/A & $86.754,00$ & $86.671,00$ & $107.473,00$ & 0,00 & 0,00 & 0,00 \\
\hline TAESA & 0,00 & 0,00 & $190.000,00$ & $197.000,00$ & $244.648,00$ & $299.954,00$ \\
\hline AES TIETE E & 0,00 & 0,00 & 0,00 & 0,00 & 0,00 & $59.983,00$ \\
\hline TRAN PAULIST & $254.540,00$ & $127.900,00$ & $31.921,00$ & $30.000,00$ & 0,00 & 0,00 \\
\hline
\end{tabular}

Fonte: Elaborada pelos autores.

As empresas ALUPAR, CESP, COELCE, CPFL ENERGIA, CPFL RENOVÁVEL, ENEVA, ENERGISA, EQUATORIAL e RENOVA não constam nessa tabela devido ao fato de não terem distribuído JCP em nenhum dos anos que compõem o horizonte tempora desse estudo (2011-2016). Observa-se que em alguns casos isso se justifica pelo fato de a empresa apresentar prejuízo no período, situação na qual é legalmente vedada a distribuição de resultados no Brasil. Mas em outros, sugere-se que pode ser uma opção da própria empresa em não adotar o JCP como uma forma de distribuição de resultados. Da amostra estudada, foi possível constatar que mesmo com a possibilidade de optar pela distribuição de resultados por meio de JCP, muitas empresas remuneraram seus acionistas por meio de dividendos, o que poderia ser em função da isenção de impostos para estes, mas nesta situação não há benefício fiscal para empresa. Na Tabela 2 são apresentadas algumas estatísticas descritivas das empresas que pagaram JCP aos seus acionistas.

Este resultado vai ao encontro de Galvão, Santos e Araújo (2018), que investigaram a política de distribuição de dividendos das empresas listadas na B3 entre 2002 e 2013 e mostraram que em quase todos os anos a maioria das empresas optaram por distribuir seus lucros apenas como dividendos, com exceção dos anos de 2003, 2004 e 2005. As empresas que utilizam apenas JCP estão em torno de $12 \%$ a $18 \%$ das empresas estudadas por esses autores.

Tabela 2 - Estatística descritiva de JCP pago (em milhares de reais)

\begin{tabular}{l|l}
\hline Média & $\mathrm{R} \$ 177.659,48$ \\
Mediana & $\mathrm{R} \$ 97.113,50$ \\
Desvio padrão & $\mathrm{R} \$ 283.254,07$ \\
Máximo & $\mathrm{R} \$ 1.700 .000,00$ \\
Soma (total) & $\mathrm{R} \$ 10.659 .569,00$ \\
Contagem & 60 \\
\hline
\end{tabular}

Pode-se observar que a média de JCP pago ao longo dos seis anos pelas 10 empresas foi superior a R $\$ 177$ milhões. O valor máximo foi de R\$ 1.7 bilhões, pagos pela CEMIG no ano de 2012. Em alguns anos não foi distribuído JCP por algumas empresas, tais como TAESA, ELETROPAULO, ELETROBRÁS, entre outras. Quando pago, o menor valor distribuído de JCP foi cerca de R\$ 14.592 milhões, pagos pela empresa ENERGIAS BR, em 2015. O desvio padrão, assim como a variância, que indicam a dispersão dos dados em torno da média, são relativamente altos, apontando para uma distribuição mais dispersa, com os valores observados tendendo a estar distantes da média. O que já era esperado devido a diferença nos tamanhos das empresas analisadas e valores de lucros disponíveis para distribuição aos seus acionistas.

De posse dos dados coletados para essa pesquisa, foi desenvolvida a simulação conforme descrito na metodologia, que apurou os valores máximos que cada empresa poderia ter distribuído via JCP e realizou a simulação da inserção desses valores nas demonstrações das empresas. Inicialmente foi considerando para distribuição do resultado, $95 \%$ do lucro líquido apresentado pelas companhias. Posteriormente, foi obtido o máximo de JCP que as companhias poderiam pagar (multiplicando o Patrimônio Líquido pelo TJLP do respectivo período). Em seguida, conforme determina a legislação comparou-se com $50 \%$ do lucro do período e das reservas de lucros e finalmente foi definido o montante de JCP a ser utilizado na pesquisa.

Cabe então, destacar algumas informações: (i) períodos nos quais as empresas tiveram prejuízo não foram considerados, fundamentando-se no princípio da prudência; (ii) nas situações em que as empresas haviam distribuído JCP, esse valor foi deduzido do máximo de JCP e apenas a diferença foi utilizada no estudo; (iii) o limite para dedução fiscal foi considerado como parâmetro principal; (iv) para determinar o ganho fiscal foi considerada a alíquota de dedução de $34 \%$ sobre o valor de JCP distribuído, conforme legislação vigente. Na Tabela 3 são apresentados os resultados das simulações com a análise consolidada para todo período. 
Tabela 3 - Metodologia do cálculo do JCP (em milhares de reais)

\begin{tabular}{|c|c|c|c|c|c|}
\hline Empresas & $\begin{array}{c}\text { Máximo de JCP } \\
(2011-2016)\end{array}$ & $\begin{array}{c}\text { Lucro } 50 \% \\
(2011-2016)\end{array}$ & $\begin{array}{l}\text { Reservas de } \\
\text { Lucros } 50 \% \\
(2011-2016)\end{array}$ & $\begin{array}{c}\text { Definição JCP } \\
\text { (2011-2016) }\end{array}$ & $\begin{array}{c}\text { Lucro máximo } \\
\text { Periodo } \\
\text { (2011-2016) }\end{array}$ \\
\hline ALUPAR & $771.328,00$ & $1.822 .763,00$ & $2.333 .403,00$ & $771.328,00$ & $3.463 .249,00$ \\
\hline CESP & $2.000 .433,00$ & $739.057,00$ & $1.668 .745,00$ & $1.278 .187,00$ & $1.404 .207,00$ \\
\hline CEMIG & $4.063 .667,00$ & $7.865 .825,00$ & $11.222 .688,00$ & $1.824 .171,00$ & $14.945 .068,00$ \\
\hline COELCE & $455.016,00$ & $1.027 .712,00$ & $1.598 .534,00$ & $455.016,00$ & $1.952 .653,00$ \\
\hline CPFL ENERGIA & $2.394 .421,00$ & $3.189 .630,00$ & $4.671 .045,00$ & $2.394 .421,00$ & $6.060 .296,00$ \\
\hline COPEL & $4.132 .422,00$ & $3.276 .883,00$ & $14.874 .282,00$ & $2.882 .312,00$ & $6.226 .077,00$ \\
\hline CPFL RENOVAV & $1.311 .849,00$ & $39.599,00$ & $175.659,00$ & $75.238,00$ & $75.238,00$ \\
\hline ENGIE BRASIL & $1.815 .576,00$ & $4.408 .743,00$ & $8.047 .349,00$ & $118.269,00$ & $8.376 .611,00$ \\
\hline ELETROBRAS & $21.389 .689,00$ & $3.637 .648,00$ & $9.638 .515,00$ & $5.831 .333,00$ & $6.911 .530,00$ \\
\hline ELETROPAULO & $758.416,00$ & $973.680,00$ & $3.070 .375,00$ & $685.377,00$ & $1.849 .992,00$ \\
\hline ENERGIAS BR & $1.928 .112,00$ & $2.429 .196,00$ & $6.024 .320,00$ & $1.152 .757,00$ & $4.615 .472,00$ \\
\hline ENEVA & $947.820,00$ & $12.986,00$ & $79.788,00$ & $130.255,00$ & $130.255,00$ \\
\hline ENERGISA & $593.528,00$ & $603.339,00$ & $2.211 .445,00$ & $593.528,00$ & $1.146 .343,00$ \\
\hline EQUATORIAL & $919.586,00$ & $1.572 .844,00$ & $2.806 .413,00$ & $919.586,00$ & $2.988 .404,00$ \\
\hline LIGHT S/A & $845.229,00$ & $1.026 .952,00$ & $1.999 .301,00$ & $564.331,00$ & $1.951 .208,00$ \\
\hline RENOVA & $275.516,00$ & $62.232,00$ & $23.209,00$ & $26.344,00$ & $118.240,00$ \\
\hline TAESA & $1.249 .294,00$ & $2.246 .608,00$ & $1.807 .461,00$ & $348.422,00$ & $4.268 .554,00$ \\
\hline AES TIETE E & $868.298,00$ & $2.943 .123,00$ & $1.295 .594,00$ & $823.131,00$ & $5.591 .933,00$ \\
\hline TRAN PAULIST & $2.034 .151,00$ & $3.818 .461,00$ & $7.237 .860,00$ & $1.589 .790,00$ & $7.255 .075,00$ \\
\hline
\end{tabular}

Fonte: Elaborada pelos autores.

Na Tabela 4 são apresentados os valores obtidos de JCP para as 19 empresas., limitado ao teto máximo de dedução permitido legalmente.

Tabela 4 - Simulação de JCP (em milhares de reais)

\begin{tabular}{l|c|c|c|c|c|l}
\hline & $\mathbf{2 0 1 1}$ & $\mathbf{2 0 1 2}$ & $\mathbf{2 0 1 3}$ & $\mathbf{2 0 1 4}$ & $\mathbf{2 0 1 5}$ & $\mathbf{2 0 1 6}$ \\
\hline TJLP & $6,00 \%$ & $5,75 \%$ & $5,00 \%$ & $5,00 \%$ & $6,25 \%$ & $6,25 \%$ \\
ALUPAR & $91.987,98$ & $93.962,53$ & $128.047,75$ & $121.868,80$ & $154.175,06$ & $181.286,06$ \\
CESP & $232.721,50$ & $252.149,00$ & $407.378,50$ & $486.846,05$ & $314.391,50$ & $306.470,50$ \\
CEMIG & 0,00 & 0,00 & $69.792,15$ & $310.628,95$ & $605.089,63$ & $838.660,38$ \\
COELCE & 88.261 & 89.743 & 78.095 & 85.608 & 53.154 & 60.154 \\
CPFL ENERGIA & $376.622,10$ & $365.759,34$ & $331.311,55$ & $339.882,10$ & $468.054,69$ & $512.790,88$ \\
COPEL & $201.085,78$ & $487.699,93$ & $403.409,00$ & $587.686,25$ & $618.772,25$ & $583.659,19$ \\
CPFL RENOVAV & $38.726,50$ & $43.007,50$ & $26.142,50$ & $24.396,50$ & $22.596,00$ & $20.790,00$ \\
ENGIE BRASIL & $33.987,08$ & $4.257,46$ & 0,00 & $33.362,75$ & $52.910,19$ & 0,00 \\
ELETROBRAS & $4.236 .909,12$ & $3.511 .920,82$ & $3.023 .481,00$ & $2.980 .635,60$ & $3.584 .604,56$ & $2.823 .281,31$ \\
ELETROPAULO & $75.138,02$ & $126.473,55$ & $121.082,15$ & $119.659,65$ & $158.085,31$ & $204.598,00$
\end{tabular}




\begin{tabular}{l|c|c|c|c|c|c}
\hline & $\mathbf{2 0 1 1}$ & $\mathbf{2 0 1 2}$ & $\mathbf{2 0 1 3}$ & $\mathbf{2 0 1 4}$ & $\mathbf{2 0 1 5}$ & $\mathbf{2 0 1 6}$ \\
\hline ENERGIAS BR & $155.761,36$ & $145.593,58$ & $211.765,00$ & $120.880,00$ & $363.225,31$ & $155.531,31$ \\
& 0,00 & 0,00 & 0,00 & 0,00 & $224.188,38$ & $723.632,06$ \\
ENERGISA & $78.256,50$ & $85.250,54$ & $93.166,80$ & $98.011,50$ & $143.230,75$ & $238.842,69$ \\
EQUATORIAL & $55.327,68$ & $125.866,06$ & $123.290,95$ & $143.585,20$ & $218.591,50$ & $252.924,31$ \\
LIGHT S/A & $78.187,08$ & $61.341,30$ & $48.739,75$ & $165.825,95$ & $210.237,06$ & $191.852,88$ \\
RENOVA & 0,00 & 0,00 & $3.135,50$ & 0,00 & $23.208,50$ & 0,00 \\
TAESA & $150.501,24$ & $129.517,14$ & $25.253,20$ & $14.231,60$ & $28.918,56$ & 0,00 \\
AES TIETE E & $221.208,36$ & $195.797,62$ & $172.981,55$ & $164.683,30$ & $68.459,94$ & 0,00 \\
TRAN PAULIST & $17.826,04$ & $164.098,23$ & $213.701,35$ & $228.252,25$ & $333.512,81$ & $632.399,38$ \\
\hline
\end{tabular}

Fonte: Elaborada pelos autores.

É possível observar na simulação acima que algumas empresas não teriam mudanças na distribuição de JCP. Tal fato é decorrência de períodos de prejuízos de tais empresas, ou ainda ao fato de já terem realizado a distribuição de JCP ao valor máximo de dedutibilidade fiscal, como no caso da CEMIG nos anos de 2011 e 2012, da ENERGIE BRASIL no ano de 2013, da ENEVA nos anos de 2011, 2012, 2013 e 2014 e da RENOVA nos anos de 2011, 2012, 2014 e 2016. Conforme mencionado anteriormente, o pagamento de JCP tem os limites legais definidos para alcance do benefício fiscal. No entanto, em grande parte das empresas estudadas, é possível a distribuição de lucros através do pagamento de JCP, o que resultaria em ganho fiscal por parte da mesma (vide Tabela 5). Ao tomarmos a ELETROBRAS como exemplo, percebe-se que a companhia poderia ter distribuído um montante superior a $\mathrm{R} \$ 20$ bilhões ao longo dos seis anos que compuseram o estudo. Da mesma forma, a COPEL poderia ter pagado mais de R 2,88 bilhões em JCP, tendo como resultado em ganho fiscal de quase R $\$ 1$ bilhão. Da mesma forma como feito para os valores reais de JCP distribuídos, na Tabela 5 são apresentadas estatísticas descritivas para os resultados dessa simulação.

Tabela 5 - Estatística descritiva da simulação de JCP (em milhares de reais)

\begin{tabular}{l|l}
\hline Média & $\mathrm{R} \$ 341.175,81$ \\
Mediana & $\mathrm{R} \$ 128.782,44$ \\
Máximo & $\mathrm{R} \$ 4.236 .909,12$ \\
Soma & $\mathrm{R} \$ 38.894 .042,91$ \\
Contagem & 114 \\
\hline
\end{tabular}

Fonte: Elaborada pelos autores.

Nota-se que a média de JCP que poderia ter sido pago pelas 19 companhias presentes no estudo foi superior a R\$ 341 milhões. O valor máximo foi de R \$ 4,23 bilhões, pagos pela ELETROBRAS no ano de 2011. Em alguns anos não foi sugerido distribuir JCP por algumas empresas, tais como CEMIG, ENERGIE BRASIL, ENEVA e RENOVA, por já terem distribuído JCP acima do limite dedutível. Esse novo cenário de maior distribuição de resultados via JCP acarretaria um ganho fiscal pelas empresas, dado que há um benefício fiscal quando da distribuição de JCP. Os valores do ganho fiscal por empresa e por ano são apresentados na Tabela 6.

Tabela 6 - Ganho fiscal (em milhares de reais)

\begin{tabular}{l|c|c|c|c|c|c}
\hline & $\mathbf{2 0 1 1}$ & $\mathbf{2 0 1 2}$ & $\mathbf{2 0 1 3}$ & $\mathbf{2 0 1 4}$ & $\mathbf{2 0 1 5}$ & $\mathbf{2 0 1 6}$ \\
\hline ALUPAR & $31.275,91$ & $31.947,26$ & $43.536,24$ & $41.435,39$ & $52.419,52$ & $61.637,26$ \\
CESP & $35.071,66$ & $85.730,66$ & - & $165.527,66$ & $1.706,80$ & $98.545,69$ \\
CEMIG & - & - & $23.729,33$ & $105.613,84$ & $205.730,47$ & $108.125,54$ \\
COELCE & $30.008,85$ & $30.512,66$ & $26.552,40$ & $29.106,86$ & $18.072,32$ & $20.452,32$ \\
CPFL ENERGIA & $128.051,51$ & $124.358,18$ & $112.645,93$ & $115.559,91$ & $159.138,59$ & $174.348,90$ \\
COPEL & $68.369,17$ & $165.817,97$ & $137.159,06$ & $199.813,33$ & $210.382,57$ & $198.444,12$
\end{tabular}




\begin{tabular}{l|c|c|c|c|c|c}
\hline & $\mathbf{2 0 1 1}$ & $\mathbf{2 0 1 2}$ & $\mathbf{2 0 1 3}$ & $\mathbf{2 0 1 4}$ & $\mathbf{2 0 1 5}$ & $\mathbf{2 0 1 6}$ \\
\hline CPFL RENOVAV & - & - & - & - & - \\
ENGIE BRASIL & $11.555,61$ & $1.447,54$ & - & $11.343,34$ & $17.989,46$ & - \\
ELETROBRAS & $1.440 .549,10$ & - & - & - & - & $959.915,65$ \\
ELETROPAULO & $25.546,93$ & $43.001,01$ & $41.167,93$ & - & $53.749,01$ & $69.563,32$ \\
ENERGIAS BR & $52.958,86$ & $49.501,82$ & $72.000,10$ & $41.099,20$ & $123.496,61$ & $52.880,65$ \\
ENEVA & - & - & - & - & $25.136,54$ & - \\
ENERGISA & $26.607,21$ & $28.985,18$ & $31.676,71$ & $33.323,91$ & 0,00 & $81.206,51$ \\
EQUATORIAL & $18.811,41$ & $42.794,46$ & $41.918,92$ & $48.818,97$ & $74.321,11$ & $85.994,27$ \\
LIGHT S/A & $26.583,61$ & $20.856,04$ & $16.571,52$ & $56.380,82$ & $71.480,60$ & - \\
RENOVA & - & - & - & - & - & - \\
TAESA & $51.170,42$ & $44.035,83$ & $8.586,09$ & $4.838,74$ & $9.832,31$ & - \\
AES TIETE E & $75.210,84$ & $66.571,19$ & $58.813,73$ & $55.992,32$ & $23.276,38$ & - \\
TRAN PAULIST & $6.060,85$ & $55.793,40$ & $72.658,46$ & $77.605,77$ & $113.394,36$ & $215.015,79$ \\
\hline
\end{tabular}

Fonte: Elaborada pelos autores.

Constata-se que as empresas, se optassem pela distribuição de lucros via JCP no período analisado, poderiam obter uma média de ganho fiscal superior a $\mathrm{R} \$ 68$ milhões. O máximo de benefício seria de cerca de R $\$ 1,4$ bilhões pela ELETROBRAS, no ano de 2011, e o mínimo seria por volta de R\$ 1,4 milhões obtidos pela ENGIE BRASIL. Dessa forma, por meio das análises foi possível observar que o uso de JCP como forma de distribuição de resultados, em detrimento do pagamento de dividendos e obedecendo aos seus limites legais, pode gerar notáveis ganhos para as empresas, corroborando com o apontado nos estudos de Malaquias et al. (2007) e Fagundes e Petri (2017). Galvão et al. (2018) aponta que os gestores em sua maioria

optam por manter a prática de pagar, ou não, dividendos, bem como a forma de distribuição. No entanto, conforme observado, as empresas podem se beneficiar do ganho fiscal ao optar pela distribuição de lucros via JCP.

\section{CONSIDERAÇÕES FINAIS}

Esse estudo buscou analisar os impactos decorrentes da escolha entre dividendos e JCP nas empresas de maior representatividade do setor elétrico, no período de 2011 a 2016, tendo como pano de fundo a otimização tributária, sob a ótica da empresa. Apesar de apresentarem similaridades conceituais perante a legislação, ambas as formas de distribuição de resultados possuem diferenças quanto ao regime de tributação em que estão inseridas.

Durante o período amostral, verificou-se que quaisquer uma das vezes que se utilizou a distribuição de lucros pela composição entre dividendos e JCP, foi possibilitado um ganho fiscal para a empresa, gerando um impacto na carga tributária. Mesmo com as limitações legais e/ou operacionais impostas para o uso do JCP, tal ganho, segundo a simulação, em média foi superior a $\mathrm{R} \$ 68$ milhões, apontando o benefício de se considerar uma combinação de distribuição de resultados. Vale ressaltar que essa é uma visão unidimensional, que não se atenta aos acionistas, e sim às empresas analisadas.

No tocante às limitações da pesquisa, deve-se destacar que as empresas estudadas se limitaram apenas ao setor elétrico. Outra limitação da pesquisa foi a análise ter se voltado apenas para a ótica da empresa, uma vez que, não considerou a visão do acionista e nem a distribuição de JCP para acionista pessoa jurídica, cuja tributação é diferente. A intenção do estudo foi de demostrar o ganho fiscal gerado pela escolha de distribuição de lucro por meio de JCP na ótica da companhia pagante. Cabe ressaltar também que resultados aqui encontrados podem ser interpretados como uma tendência, porém não devem ser generalizados.

Nesse sentido, propõe-se para pesquisas futuras a análise com uma amostra composta por empresas de diferentes setores, ou outras empresas do setor elétrico, diferentes das estudadas aqui. É possível também o estudo individual de cada empresa da amostra do presente estudo, por meio de estudo único de caso.

\section{REFERÊNCIAS}

Baker, H. K., \& Smith, D. M. (2006). In search of a residual dividend policy. Review of Financial Economics, 15(1), 1-18.

Brasil. Lei $n$. 6404, de 15 de dezembro de 1976. Disponível: <http://www.planalto.gov.br>. Acesso em: 15 de maio de 2018.

Brasil. Lei $n$. 9249, de 26 de dezembro de 1995. Disponível: www.receita.fazenda.gov.br/ [acesso em 15 de maio 2018]. 
Brito, M. (1999). Planejamento tributário: imposto de renda. Vila Velha: SEDES/UVV.

Cioffi, P. L. D. M., \& Famá, R. (2010). O modelo de Ohlson e a sinalização de dividendos no mercado de capitais brasileiro. SEMINÁRIOS EM ADMINISTRAÇÃO FEA/USP-SEMEAD, XIII Anais, São Paulo.

Corso, R. M., Kassai, J. R., \& Lima, G. A. F. S. (2012). Distribuição de dividendos e de juros sobre o capital próprio versus retorno das ações. Revista de Educação e Pesquisa em Contabilidade (REPeC), 6(2).

Creswell, J. W., \& Clark, V. L. P. (2015). Pesquisa de Métodos Mistos: Série Métodos de Pesquisa. Penso Editora.

Decourt, R. F., \& Procianoy, J. L. (2012). O Processo Decisório sobre a Distribuição de Lucros das Empresas Listadas na BM \& FBOVESPA: Survey com CFOs. Revista Brasileira de Finanças, 10(4), 461-498.

Fagundes, C., \& Petri, S. M. (2017). Juros sobre capital próprio: um estudo da contribuição no resultado tributário nas empresas GOL E LATAM. Revista da UNIFEBE, 1(22), 55-86.

Forti, C. A. B., Peixoto, F. M., \& Lima, D. (2015). Fatores determinantes do pagamento de dividendos no Brasil. Revista Contabilidade \& Finanças, 26(68), 167-180.

Galvão, K. S., Santos, J. F., \& Araújo, J. M. (2018). Dividendos, juros sobre capital próprio e níveis de payout: Um estudo investigativo sobre a política de distribuição de dividendos adotada pelas empresas listadas na BM\&FBovespa. Revista Contemporânea de Contabilidade, 15(36), 3-30.'

Gil, A .C. (1999). Métodos e técnicas de pesquisa social. 5.ed. São Paulo: Atlas.

Gomes, P. H. C. P. N., Takamatsu, R. T., \& Machado, E. A. (2015). Determinantes da Política de Remuneração do Capital Próprio: Dividendos versus Juros sobre Capital Próprio. Reunir: Revista de Administração, Contabilidade e Sustentabilidade, 5(2).

Gordon, M. J. (1959). Dividends, earnings, and stock prices. The review of economics and statistics, 99-105.

Gordon, M. J., \& Shapiro, E. (1956). Capital equipment analysis: the required rate of profit. Management science, 3(1), $102-110$.

Gouveia, F. H. C., \& Afonso, L. E. (2012). Uma análise das formas de remuneração dos sócios por meio do planejamento tributário. Revista de Administração Mackenzie (Mackenzie Management Review), 14(2).

Iquiapaza, R. A, Lamounier, W. M \& Amaral, H. F. (2006). Assimetria de informações e pagamento de proventos em dinheiro na Bovespa. In: Encontro Nacional da Associação Nacional dos Programas de Pós-Graduação em Administração, 30, 2006, Salvador. Anais eletrônicos. Salvador: ANPAD.

Lintner, J. (1956). Distribution of incomes of corporations among dividends, retained earnings, and taxes. The American economic review, 46(2), 97-113.

Loss, L., \& Sarlo Neto, A. (2003). Política de dividendos, na prática, é importante? Revista Contabilidade \& Finanças, 14(SPE), 39-53.

Malaquias, R. F., Giachero, O. S., da Costa, B. E., \& Lemes, S. (2009). Juros sobre o capital próprio: uma análise envolvendo a empresa pagadora e o acionista recebedor. Revista Contabilidade, Gestão e Governança, 10(2).

Miller, M., \& Modigliani, F. (1961). Dividend policy, growth, and the valuation of shares. The Journal of Business, 34, 411-433.

Oliveira, F. A. (2018). As reformas tributárias no plano internacional: a marcha da insensatez In: FAGNANI, E. A Reforma Tributária Necessária: diagnóstico e premissas. $1^{\circ} \mathrm{ed}$. Brasília: ANFIP: FENAFISCO: São Paulo: Plataforma Política Social.

Sá, A. L. \& Sá, A. M. L. (1990). Dicionário de contabilidade. $8^{a}$ ed. São Paulo: Atlas.

Santos, A., \& Salotti, B. M. (2009). Juros sobre o capital Próprio-Pesquisa Empírica Para Avaliação do nível de conhecimento das Empresas sobre sua utilização. Revista Contabilidade, Gestão e Governança, 10(2).

Sanvicente, A. Z. (2017). Teoria residual da politica de dividendos: um experimento natural. FGV.

Sousa Neto, J. A., Jordão, R. V. D., Pinheiro, J. L., \& Marquezine, R. P. (2014). Juros sobre capital próprio como forma de remuneração de acionistas: um estudo sobre o conflito de agência e as práticas de planejamento tributário. Revista de Administração FACES Journal, 13(4), 91-108. 